\title{
Numerical Simulation of Steel Reinforced Concrete (SRC) Joints
}

\author{
Isaac Montava ${ }^{1, *}$, Ramon Irles ${ }^{1}$, Jorge Segura ${ }^{2}$, Jose Maria Gadea ${ }^{2}$ and Ernesto Juliá ${ }^{2}$ \\ 1 Departamento de Ingenieria Civil, Universitat d'Alacant, 03080 Sant Vicent del Raspeig, Spain; \\ ramon.irles@ua.es \\ 2 Departamento de Mecánica de los Medios Continuos y Teoría de las Estructuras, Universitat Politècnica de \\ València, Campus d'Alcoi, 03801 Alcoi, Spain; jsegura@mcm.upv.es (J.S.); jmgadea@mes.upv.es (J.M.G.); \\ erjusan@mes.upv.es (E.J.) \\ * Correspondence: isaac.montava@ua.es; Tel.: +0034-966528428
}

Received: 13 December 2018; Accepted: 22 January 2019; Published: 26 January 2019

\begin{abstract}
This paper presents a three-dimensional finite element model to confirm experimental tests carried out on steel reinforced concrete joints. The nonlinear behavior of this concrete is simulated, along with its reduced capability to resist large displacements in compression. The aim was to obtain the plastic behavior of reinforced concrete beams with a numerical model in the same way as obtained experimentally, in which the reduction of strength in the post-critical stage was considered to simulate behavior until structures collapsed. To do this, a nonlinear calculation was necessary to simulate the behavior of each material. Three numerical models provide a moment-curvature graph of the cross-section until collapse. Simulation of the structural elements is a powerful tool that avoids having to carry out expensive experimental tests. From the experimental results a finite element model is simulated for the non-linear analysis of steel reinforced concrete joints. It is possible to simulate the decreasing stress behavior of the concrete until reaching considerable displacement. A new procedure is discussed to capture the moment-curvature diagram. This diagram can be used in a simplified frame analysis, considering post-critical behavior for future research.
\end{abstract}

Keywords: reinforced concrete; steel-reinforced concrete; joint; reinforcement; numerical simulation; post-critical; moment-curvature

\section{Introduction}

Reinforced concrete framed structures are the most commonly used structural system in our society, especially in residential typologies. These reinforced concrete structures offer high ductility and break usually on joints when faced with seismic action, and it is necessary to analyze if reinforcement is capable of absorbing a large amount of energy to avoid failing structures. The higher ductility, the greater energy absorption becomes against earthquakes and the greater the deformation that can be achieved without structural collapsing.

According to Akiyama [1], the first controversy on flexibility and rigidity started in Japan after the Kanto earthquake. From the 1960s, a need emerged to add strength and stiffness to structures when planning to build them in areas at high seismic risk. The last step was to provide buildings with elements designed to dissipate the energy generated by earthquakes with base insulation and layers of elastomers to absorb horizontal displacement.

The three specimens were analyzed by numerical simulation to compare the results with the experimental tests. The model beam corresponded to a T-joint of a conventional frame with a concentrated load, which corresponded to a horizontal or vertical force (Figure 1). The T shape was chosen because of the test frame's characteristics. Different constructive solutions were considered 
to analyze the real behavior of the beam from the elastic to plastic range and collapse. Load was defined as a prescribed displacement located in the center of the beam to know its plastic behavior. The first model, $\mathrm{P} 03$, was a $3.6 \mathrm{~m}$ long pinned beam with a concentrated load in the center, with a steel reinforcement of four bars (12 $\mathrm{mm}$ in diameter). The second model, P04, had the same reinforcement, but with the addition of a $2 \mathrm{~m}$ long HEB-100 cross-section in the central part. The third model, P05, was a reinforced concrete beam capable of supporting a similar load to the P04 model, but without the metallic section, with a steel reinforcement of two bars (16 $\mathrm{mm}$ in diameter) and two bars $(20 \mathrm{~mm}$ in diameter) (Figure 2). Our conclusions were similar to those reached by recognized studies with more complex frames in which loads were applied in a reverse direction, such as in reference [2]. Recent research, such as in reference [3], shows that high-strength reinforced concrete structures confined with tubular profiles and embedded metal profiles display the best behavior.

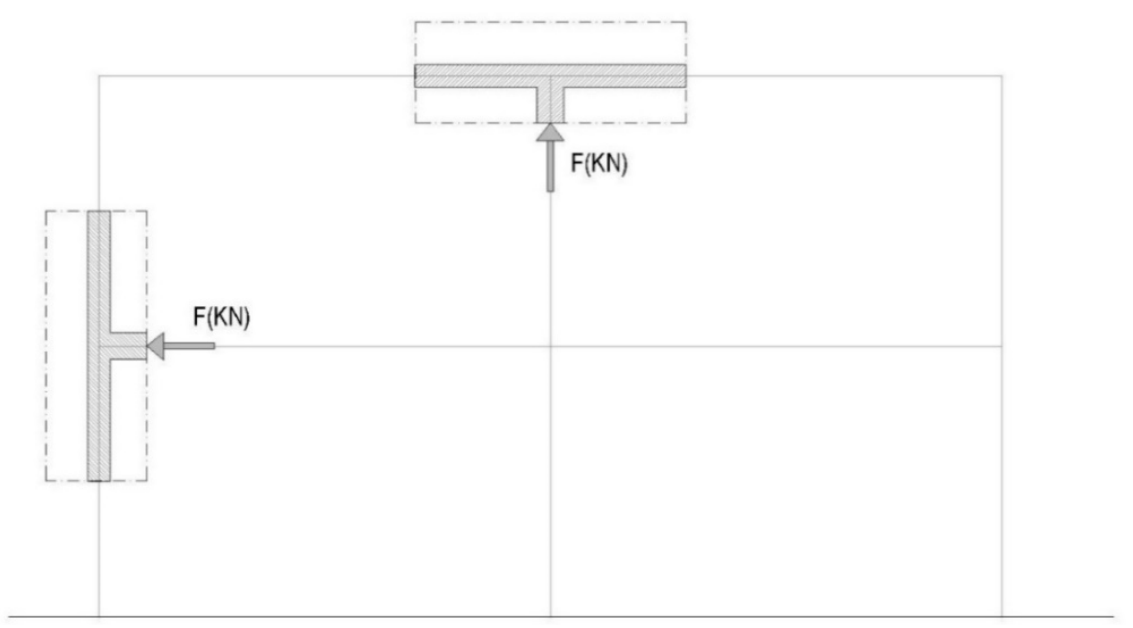

Figure 1. Detail of the T-joint in a conventional frame.

P03

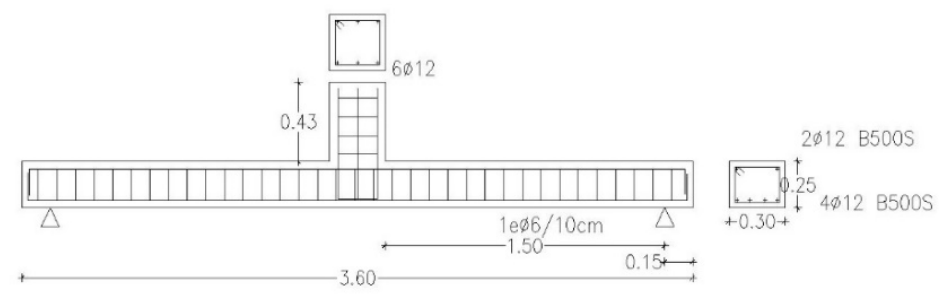

P04

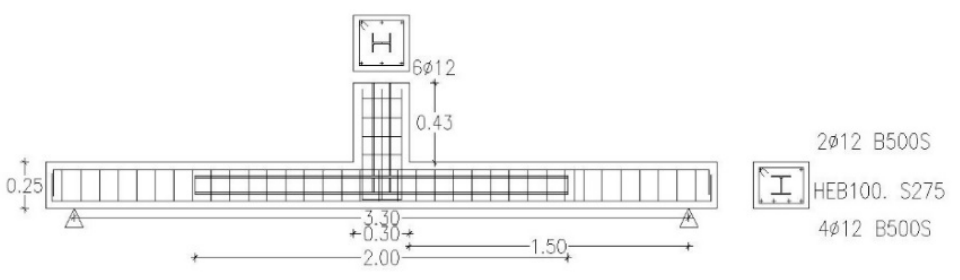

P05

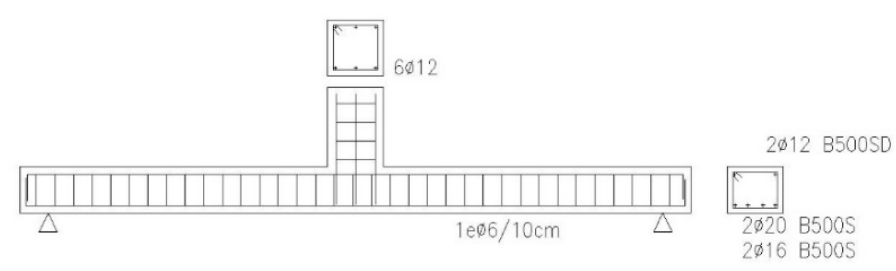

Figure 2. Models P03, P04, and P05.

Reinforced concrete is a difficult material to model with the finite element method. Wide-ranging studies have simulated the behavior of reinforced concrete with finite element software but very few have simulated the plastic region in which concrete cracks reduce its strength. 
There are several computational mechanics models to describe the behavior of concrete. Some models are focused on different approaches of the cracking process, including smeared crack, damage, and plasticity models [4-6].

In this work, the model presents the same modulus of elasticity for tension and compression in the elastic region. Otherwise, this model allows us to simulate different plastic behavior for the material in tension and compression. This is the studied case; the behavior from yield is different in tension and compression for the material.

The yield strength and isotropic hardening behavior may be different in tension and in compression. Different yield criteria and plastic flow potentials are used for tension and compression.

The tension behavior is pressure-dependent, and the Rankine maximum stress criterion is used. The compression behavior is pressure-independent, and the von Mises yield criterion is used $[7,8]$.

With Abaqus software, the numerical results were compared to the experimental results obtained in reference [9] but the models cannot simulate all the plastic regions with reduced strength until failure. Other studies have compared and introduced the solid material in Ansys to model reinforced concrete excluding the plastic region [10].

The nonlinearity and geometry of the material make it difficult to model with the finite element method [11]. A nonlinear simulation was carried out by the finite element method with the Ansys software. The simulation with a damage-based model of concrete (Solid65) did not allow large displacements and resulted in an unstable model that was not valid for the present research. It was possible to obtain images of the initial cracks of the concrete in deflections up to $10 \mathrm{~mm}$. Concrete structures reinforced with metal sections have been used in many countries with high seismic risk. In steel reinforced concrete structures, the ductility of the material and its capability to absorb energy are improved, while protecting the steel against fire [12].

Other studies such as $[13,14]$ analyze the reinforcement of structures at joints and in walls with steel sections.

The $\mathrm{PhD}$ thesis of Suswanto [15] analyzes experimentally and numerically the behavior of eight joints: Four of the steel-reinforced concrete in columns and beams (SRC), three of the steel-reinforced concrete in columns and the steel in beams (SRCS), and one steel joint in columns and beams (S). Tests were carried out with vertical cyclic loads. The moment-curvature graphs, obtained numerically by XTRACT Analysis Report software, are particularly significant. The studies of Anastasiadis, Mosoarca, and Gioncu [16] facilitate the understanding of the relationship between the capability of the rotation of a beam and its ductility. The PhD thesis by Fenollosa [17] is of special interest when analyzing the behavior of composite steel and concrete columns subjected to bending and compression.

In recent years, there have been numerous studies [18-26] analyzing the behavior of reinforced concrete joints. In particular, models with moment-curvature graphs are an interesting way to simulate the complex behavior of large structures [27].

Finite element models improve the understanding of mechanical behavior and allow new variables and alternatives to be introduced without having to conduct expensive experimental tests. These models must be adjusted, compared, and validated with the experimental results until reliable results are achieved.

\section{Objectives}

The objective of this paper is to describe the process of developing a three-dimensional model capable of reproducing the experimental tests in the thesis of the first author [28] in all the behavior stages until the material's failure.

The intention is to simulate the loss of strength of concrete in the post-critical stage in large strains with all their integrating elements to obtain a moment-curvature graph. The ultimate goal is to analyze in future research the behavior of the 2D and 3D simplified bar frames depicted by these moment-curvature graphs subjected to vertical and horizontal loads, to simulate the seismic effect and compare the results obtained in different constructive solutions. 
Figure 3 shows the experimental set-up used to test the specimens. The reinforced concrete prototypes were manufactured in the civil engineering laboratory with the HA-25 concrete. These prototypes were tested in a Servosis test frame (model ME-406/30, Servosis, Madrid, Spain), which can apply a maximum force of $300 \mathrm{kN}$.
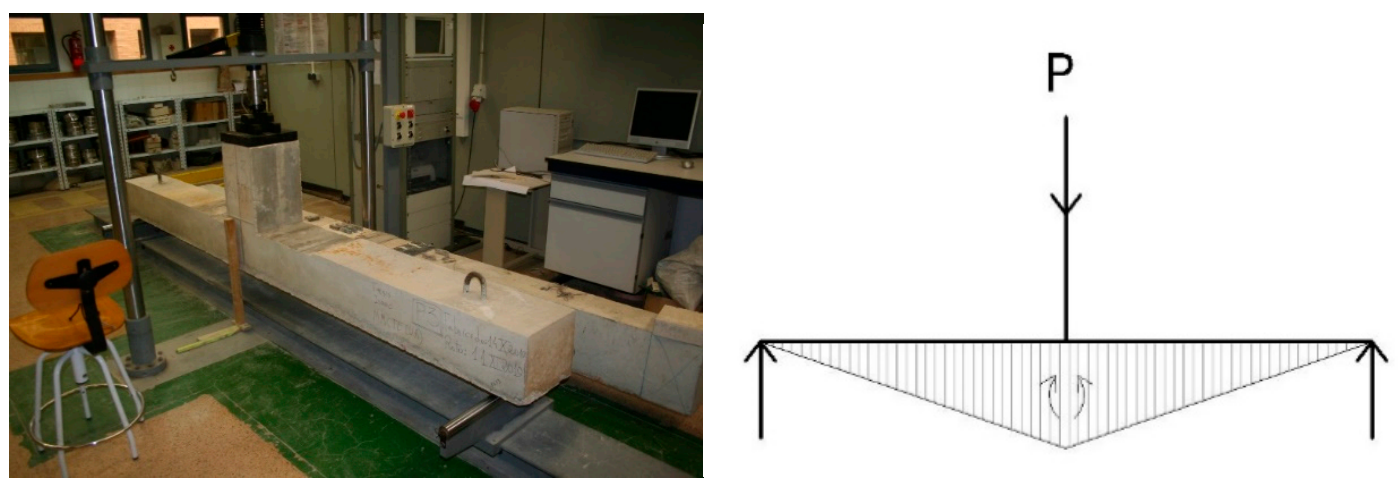

Figure 3. Experimental set-up.

The load is applied as an imposed displacement in the center of the simply supported beam. The values of the obtained displacements are repeated twice, in load-unload cycles, and they increase with a parabolic progression until the maximum value of $330 \mathrm{~mm}$.

A vertical force-displacement graph is obtained in the center of the beam.

\section{Numerical Simulation}

\subsection{Numerical Model}

The analysis of the model is nonlinear, with two nonlinearities: Material and geometry. The model was made with the APDL module in ANSYS, in its windows graphic interface, by introducing loads as displacements imposed to perform plastic simulation. To build the model, the ANSYS APDL module, versions 16.2 and 17.2, were used with the research license of the Department of Civil Engineering at the University of Alicante. The simulated specimens are described in Table 1.

Table 1. Summary of the tests carried out. RC, reinforced concrete; SRC, steel reinforced concrete in columns and beams.

\begin{tabular}{cccccc}
\hline Prototype & Typology & Beam Section $\left.\mathbf{( m m}^{\mathbf{2}}\right)$ & Bottom Frame & Profile & Distance between Supports \\
\hline P03 & HA (RC) & $300 \times 250$ & $4 ø 12$ & - & $3.30 \mathrm{~m}$ \\
P04 & HAA (SRC) & $300 \times 250$ & $4 \varnothing 12$ & HEB-100 & $3.30 \mathrm{~m}$ \\
P05 & HA (RC) & $300 \times 250$ & $2 ø 16+2 \varnothing 20$ & - & $3.30 \mathrm{~m}$ \\
\hline
\end{tabular}

Three specimens were simulated: P03 with no steel section, P04 with a steel section, and P05 with no steel section, but with P04's strength and large deflections. For the geometry, the model was divided into volumes to control the meshing process (see Figure 4). 

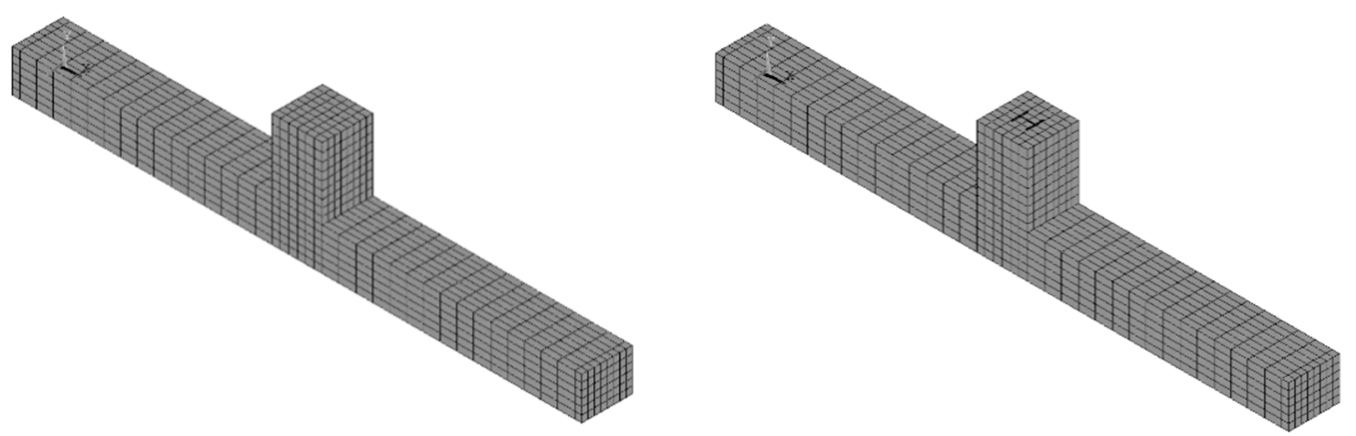

Figure 4. Prototypes P03, P04, and P05 (similar to P03 with different reinforcements), simulated with ANSYS.

To achieve the convergence of the solution, displacements were applied instead of forces.

\subsection{Materials}

In the Ansys software, the material used in the finite element model for concrete predicts the failure of quasi-brittle materials. Concrete, a quasi-brittle material, is simulated with a simplified model in which the stress-strain graph decreases in the last part after the maximum stress value (see Figure 5). An eight nodes element with three degrees of freedom in each node (Solid 185) was used for simulating concrete.

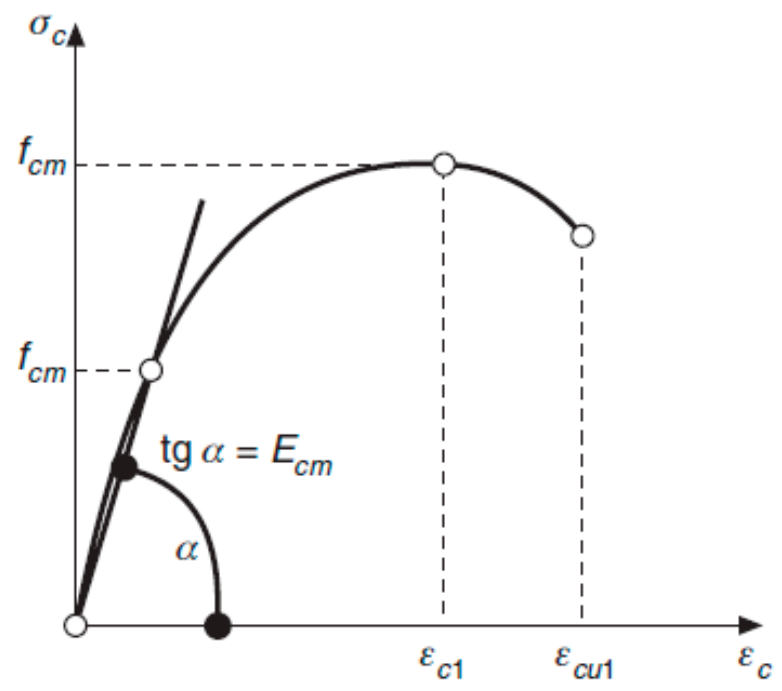

Figure 5. Stress-strain graph of concrete [29].

In this study, the fragile behavior of the material was considered with both ways of failure (tension and compression), and its strength was significantly reduced in compression to simulate the collapse. The used model material has yield strength and isotropic hardening behavior and was different in tension and in compression. It has been implemented from the stress-strain graph and obtained experimentally for solid elements (Figure 6). A model was designed in which strength decreased when displacements increased due to the cracking concrete. 


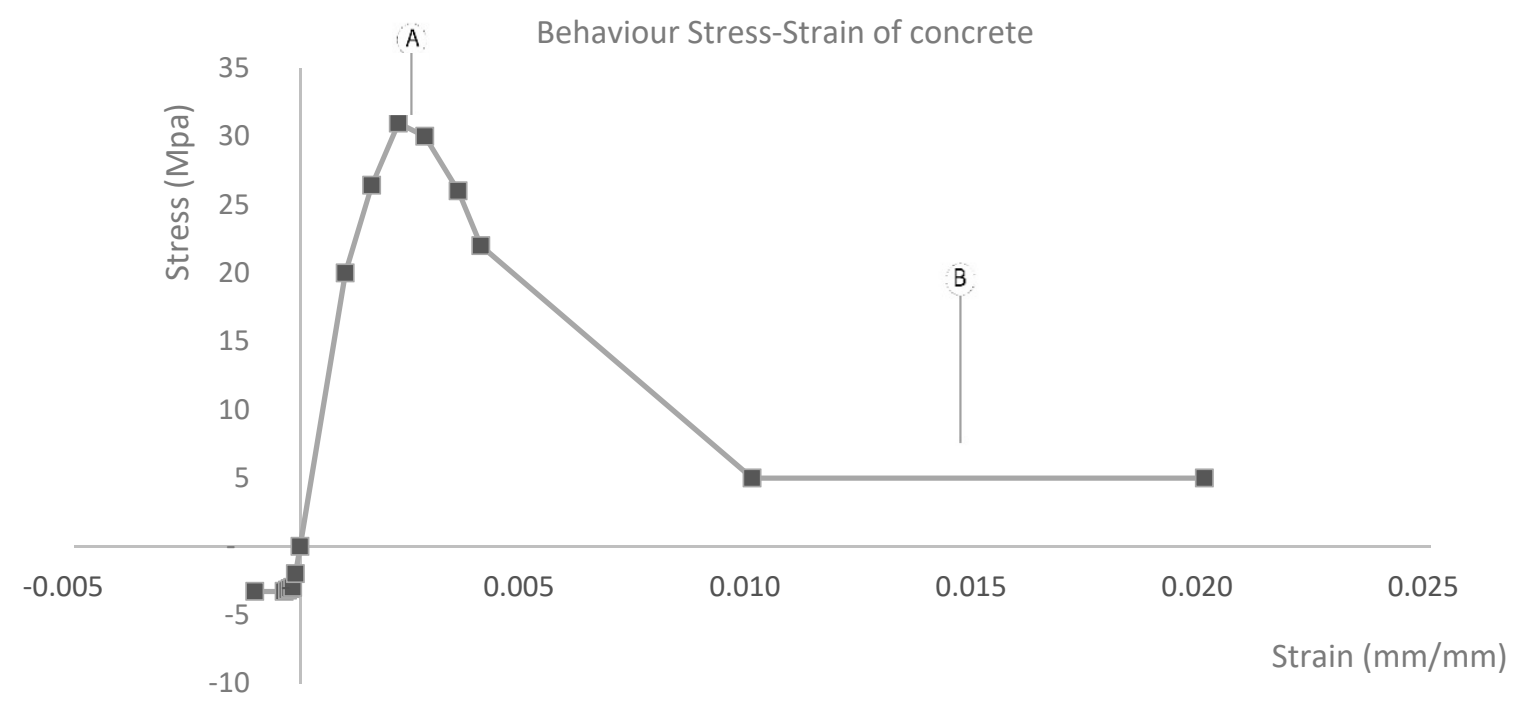

Figure 6. Stress-Strain of concrete from the numerical model.

The model materials for the reinforcing steel bars had the same properties as those tested experimentally, and the most suitable material was used in each model.

B500S steel was introduced into the model like linear elements with isotropic multilinear behavior (multilinear isotropic hardening) (Figure 7), which was similar to the experimental behavior.

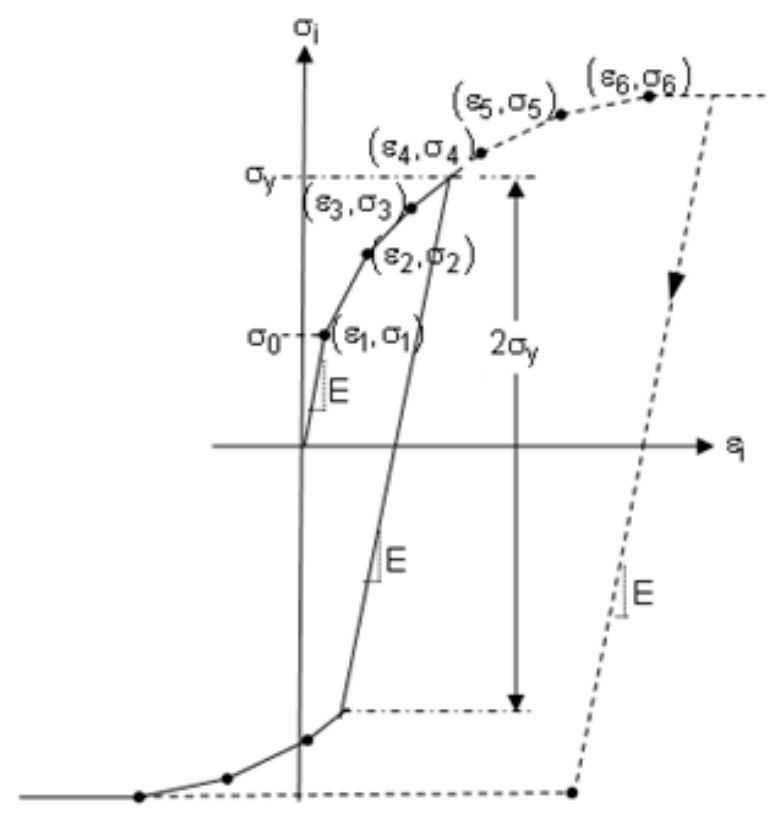

Figure 7. Multilinear isotropic hardening behavior.

All the reinforcing bars were generated using linear elements with three degrees of freedom at the ends (LINK180). The concrete and steel nodes were coincident and share the degrees of freedom. Figure 8 shows the stress-strain graph behavior introduced into the material used as reinforcing bars for the simulation. 


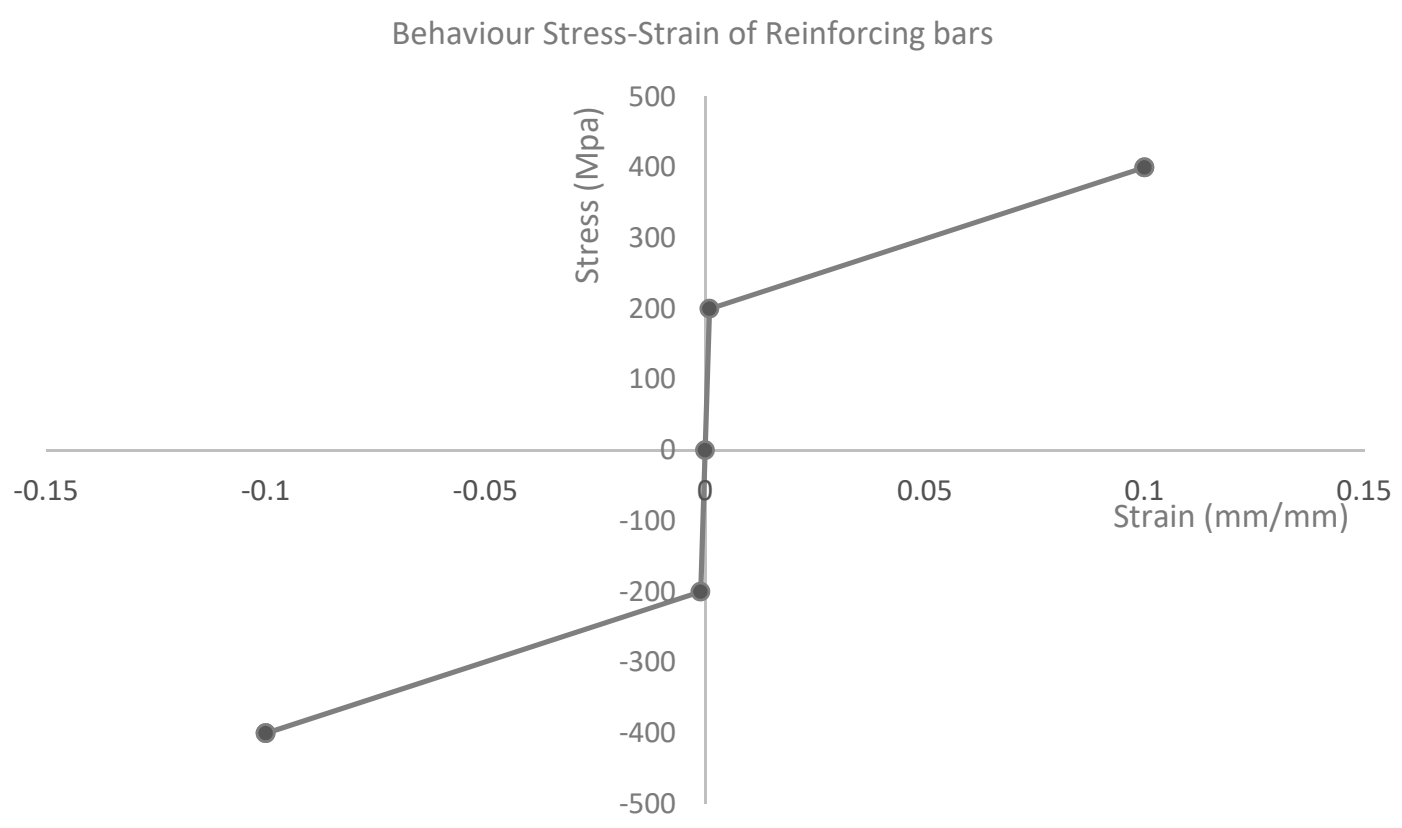

Figure 8. Detail of the stress-strain diagram of the reinforcing bars.

To generate the HEB section, a linear element of six degrees of freedom in each node (BEAM188) was used, with axial, shear, and bending capabilities. The cross-section HEB100 was assigned to this element.

The S275 steel for the section was modelled with bilinear behavior to facilitate convergence (see Figure 9), with a different elastic limit from the steel of the reinforcing bars. The modulus of elasticity was 210 GPa for both steels and Poisson's ratio was 0.3 .

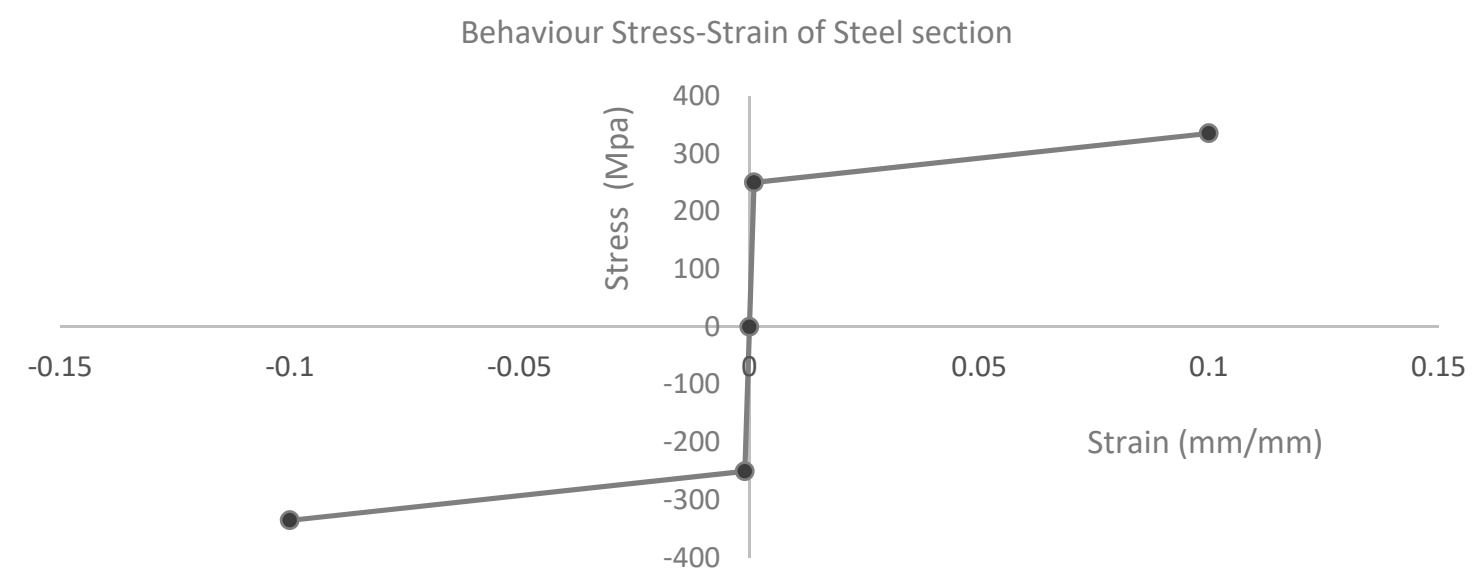

Figure 9. Stress-strain diagram of steel for the cross-section.

Eurocode 3 [30] considers plastic calculation using a graph with a residual slope in the plastic region, with slight hardening in deflection (see Figure 10). 


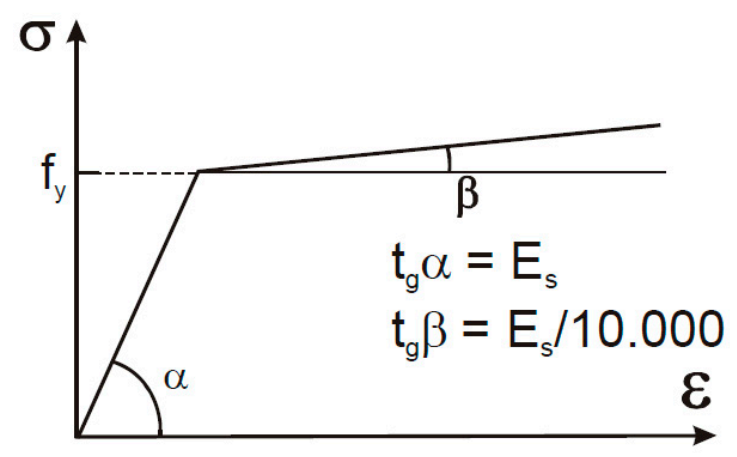

Figure 10. Stress-strain bilinear diagram, with second branch inclined for nonlinear calculations [31].

This facilitates the numerical convergence of calculations without significantly varying the results. Loss of resistant capacity was not contemplated due to steel breakage.

\section{Simulated Models}

\subsection{Reinforced Concrete Beam P03}

The models with $200 \mathrm{~mm}$ displacement at the center of the beam are presented, in which reinforcement presents plasticity. Figure 11 shows the maximum deflection.

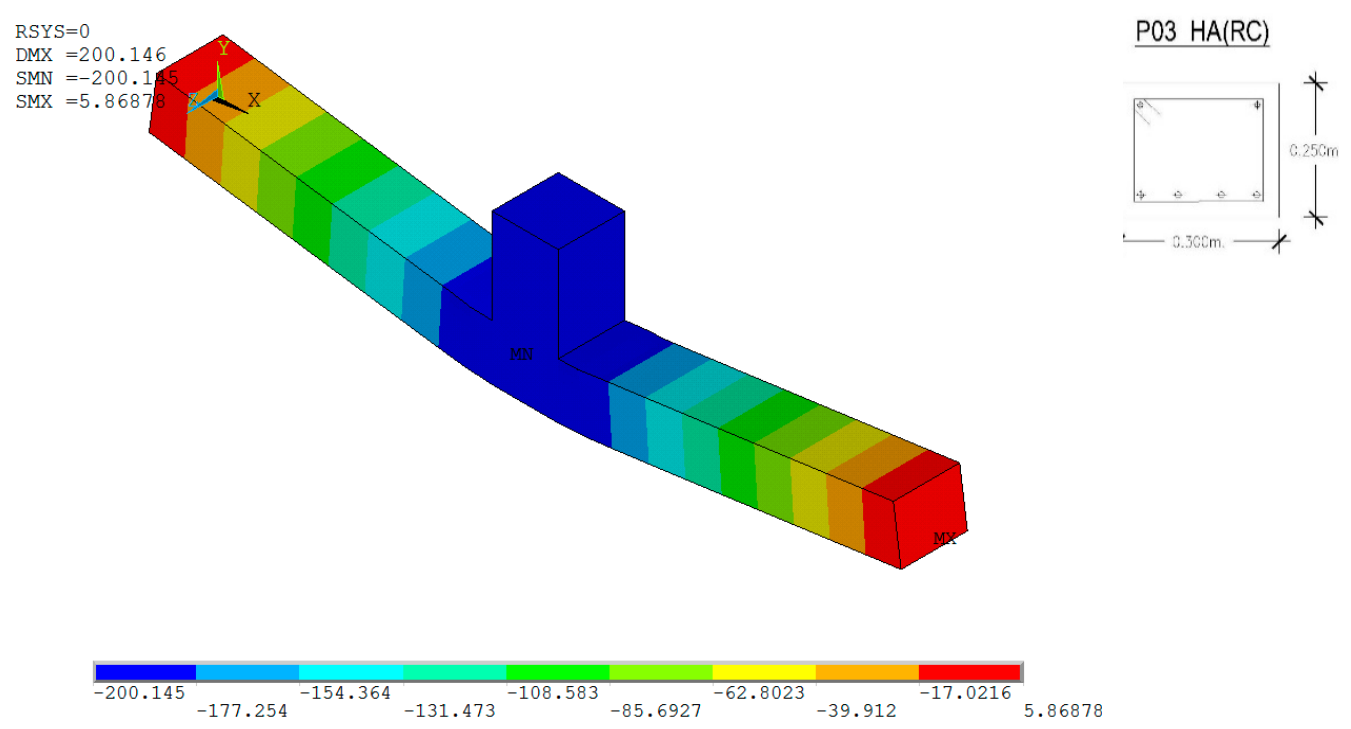

Figure 11. Deflection of the beam (in $\mathrm{mm}$ ) for the $200 \mathrm{~mm}$ deflection.

Figure 12 represents the maximum stresses in the concrete obtained with the maximum deflection of $200 \mathrm{~mm}$, where the maximum tension value was $3.49 \mathrm{MPa}$ in the lower beam part and 14.6 MPa to compression in the upper beam part. These values were below the $30 \mathrm{MPa}$ of maximum compressive strength because it was in the postcritical stage. 


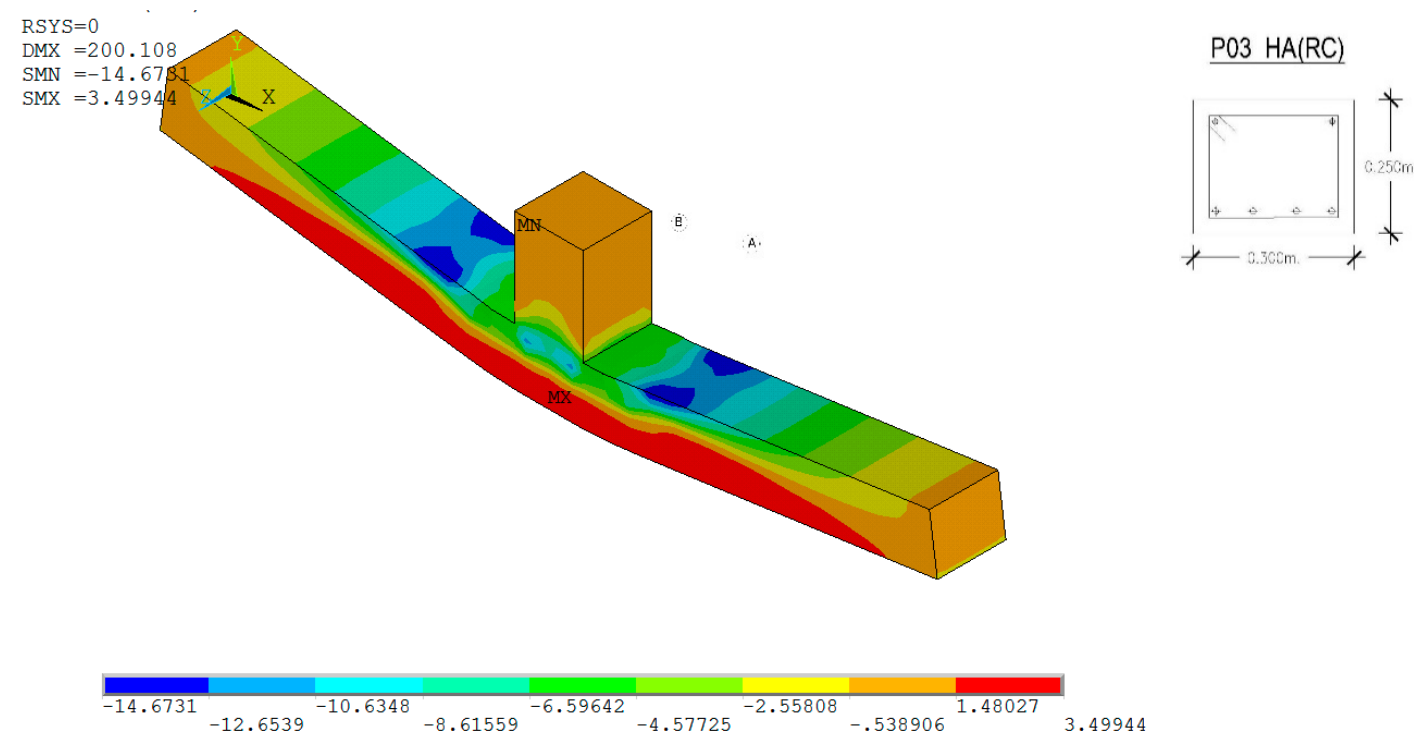

Figure 12. Stress in concrete, tension, and compression (in MPa) for a $350 \mathrm{~mm}$ deflection.

Figure 13 shows the plastic region of the upper and lower reinforcements, with a maximum stress of $376.5 \mathrm{MPa}$. The maximum stress was reached in previous stages as the maximum strain of 0.003 was very low and was achieved in the initial nonlinear calculation steps (Figure 14). The total strain of the steel and concrete in the contact areas was the same, which ensured correct adherence as nodes were coincident. The elastic strain corresponded to the elastic limit of steel of $400 \mathrm{MPa}$, which was 0.001, whose maximum value was 0.25 (see Figure 15).

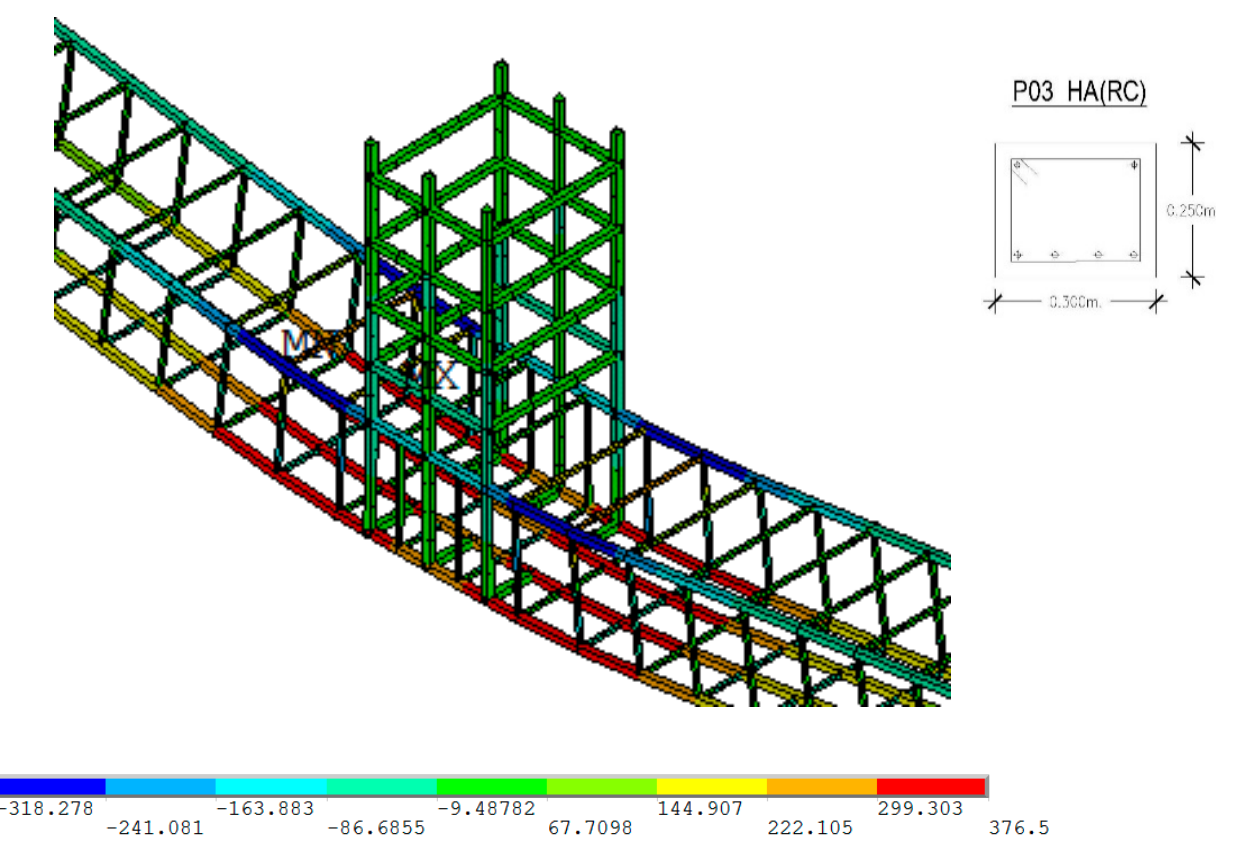

Figure 13. Stress in reinforcements, tension, and compression (in MPa) for a $350 \mathrm{~mm}$ deflection. 

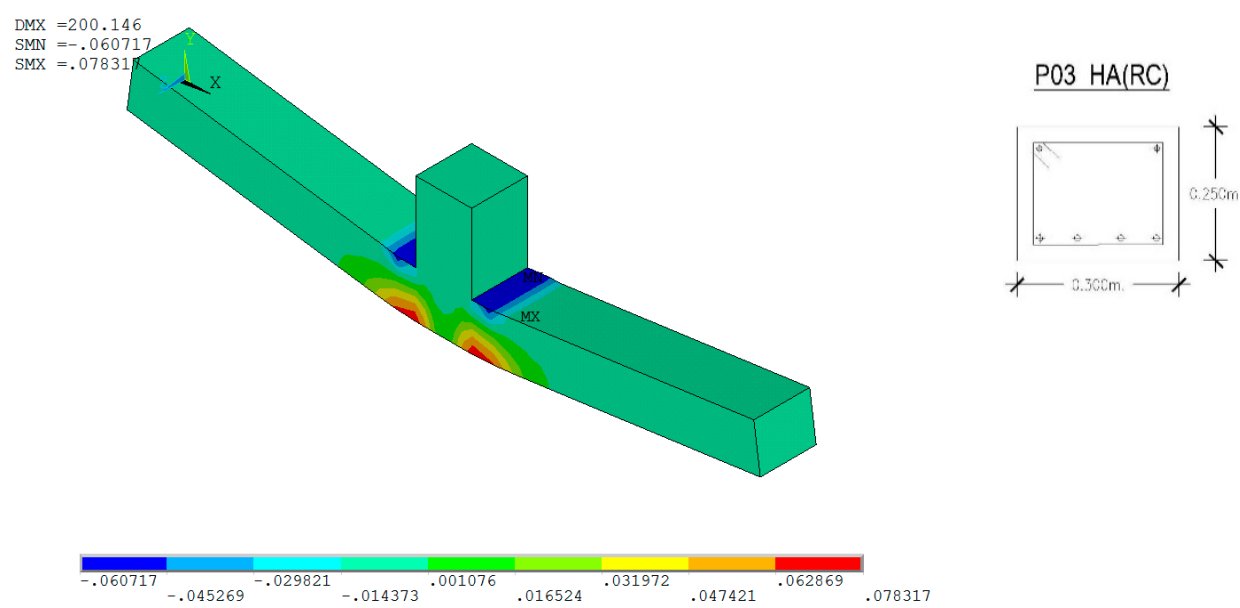

Figure 14. Plastic strain on the $x$-axis in the concrete, tension, and compression for a $350 \mathrm{~mm}$ deflection.

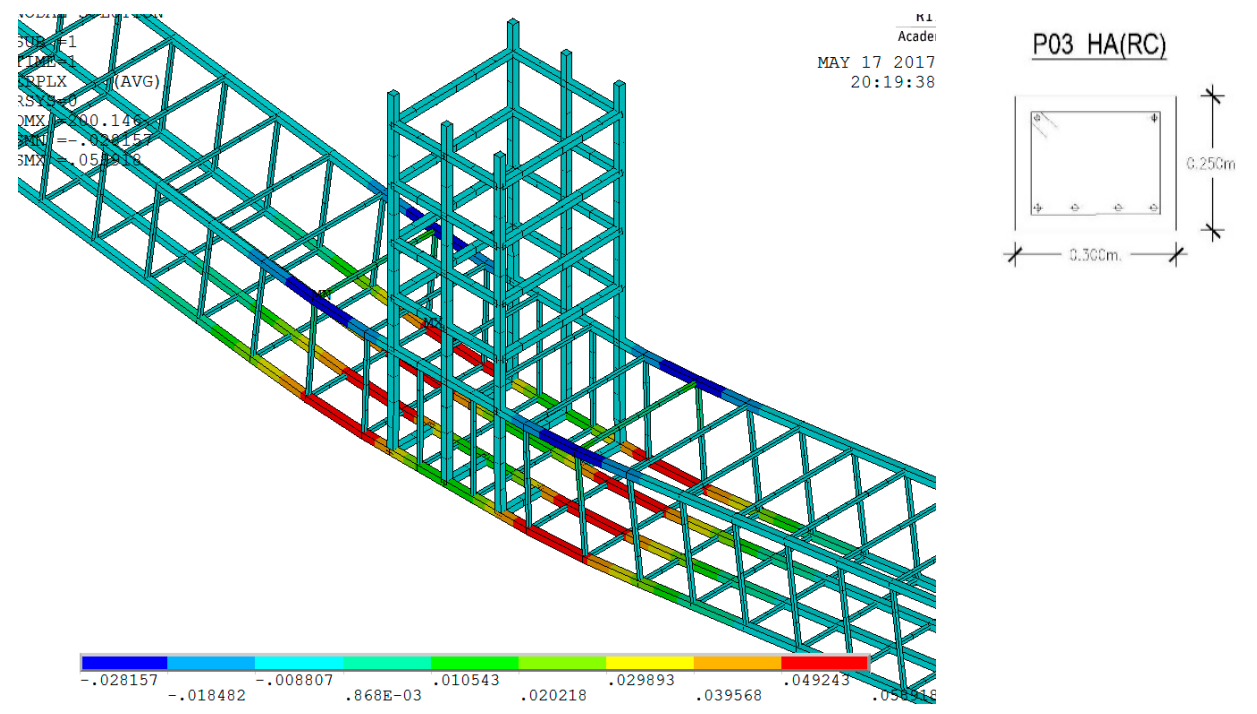

Figure 15. Plastic strain on the $x$-axis in the plasticity reinforcements, tension, and compression for a $350 \mathrm{~mm}$ deflection.

The information obtained from the evolution of the force-displacement diagram during the vertical force application was evaluated. The results were similar to those from the experimental results (see Figures 16 and 17). The three-dimensional model was able to reproduce experimental tests in the thesis of the first author of this paper [28]. Different constructive solutions of the representative beam of the gantry (see Table 1) were submitted to a growing cyclic loading and unloading process to know their real behavior in elastic and plastic phases until breakage occurred, which was achieved only in the less ductile sets. Load was introduced as a displacement imposed on the center of the beam. Figure 17 shows the envelope curve of the real test. 


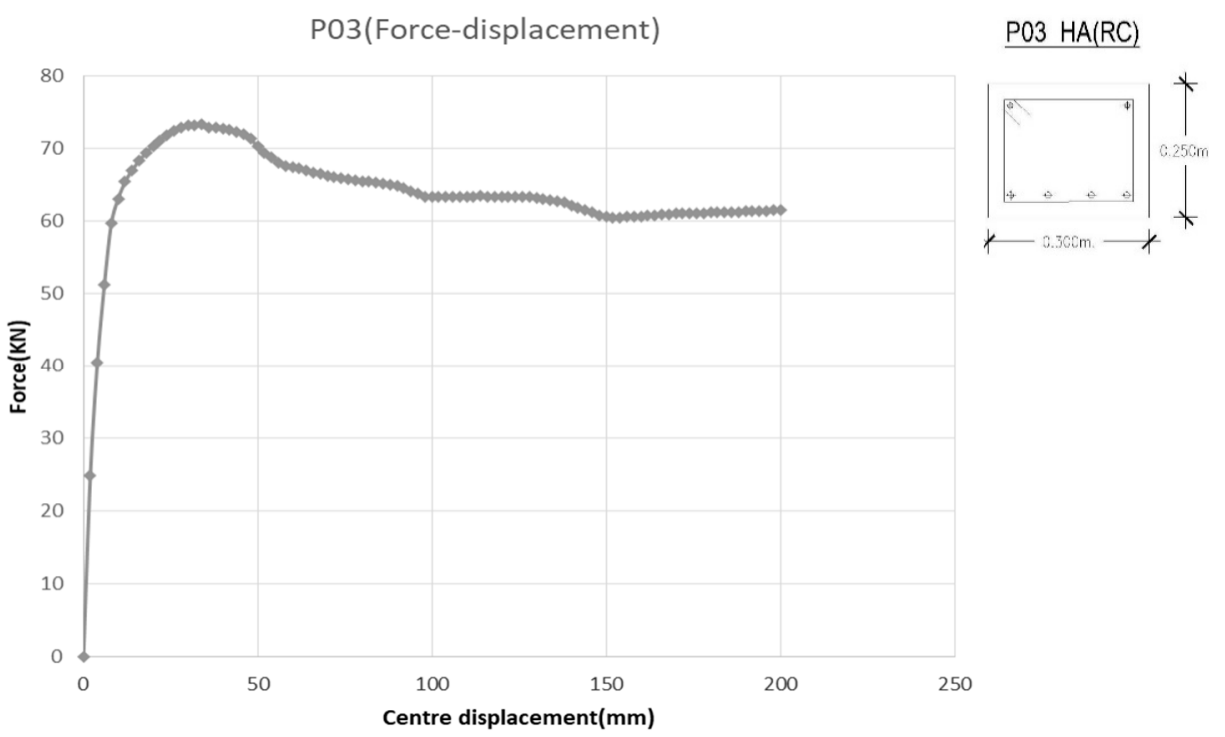

Figure 16. Force-displacement diagram of beam P03 from the numerical model.

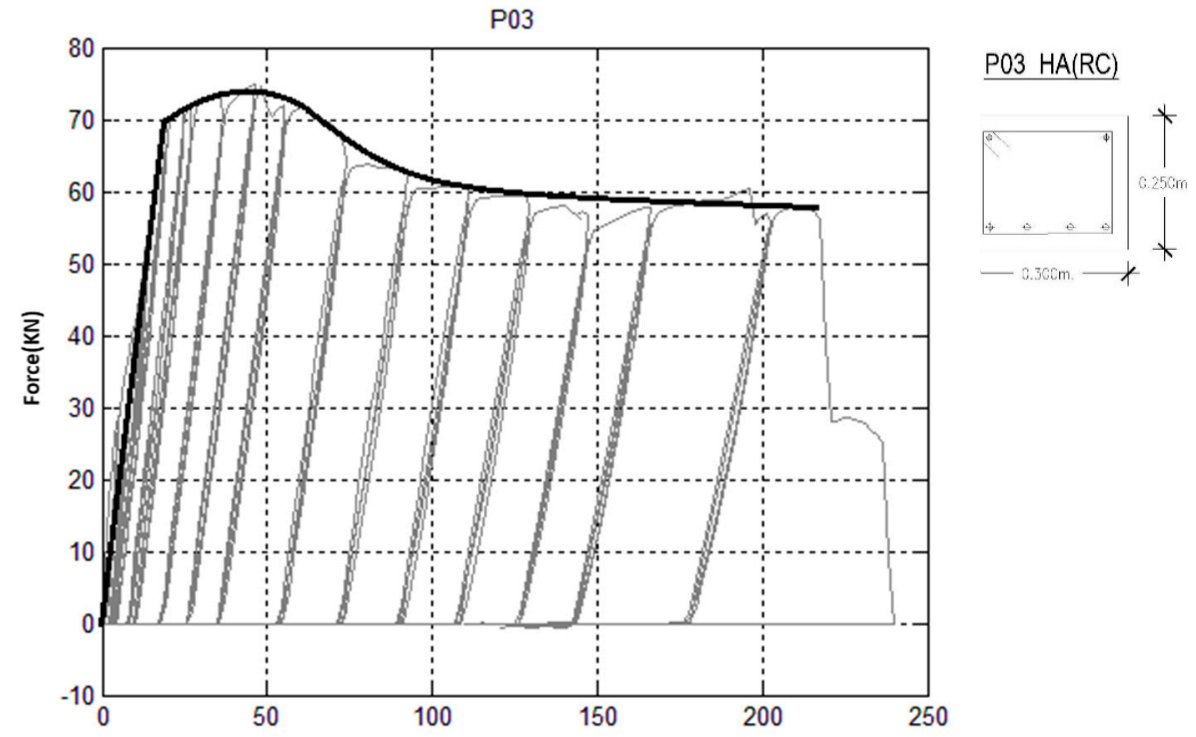

Centre displacement $(\mathrm{mm})$

Figure 17. Force-displacement diagram of beam P03 from the experimental results.

By introducing the concrete material with the elastoplastic behavior with a decreasing final part in the graph, the results were comparable to those obtained experimentally.

\subsection{Steel-Reinforced Concrete Beam P04}

The second model to be analyzed was an HEB100 cross-section embedded in the center of the section. The deflection at the center of the beam reached $350 \mathrm{~mm}$ (see Figure 18). 


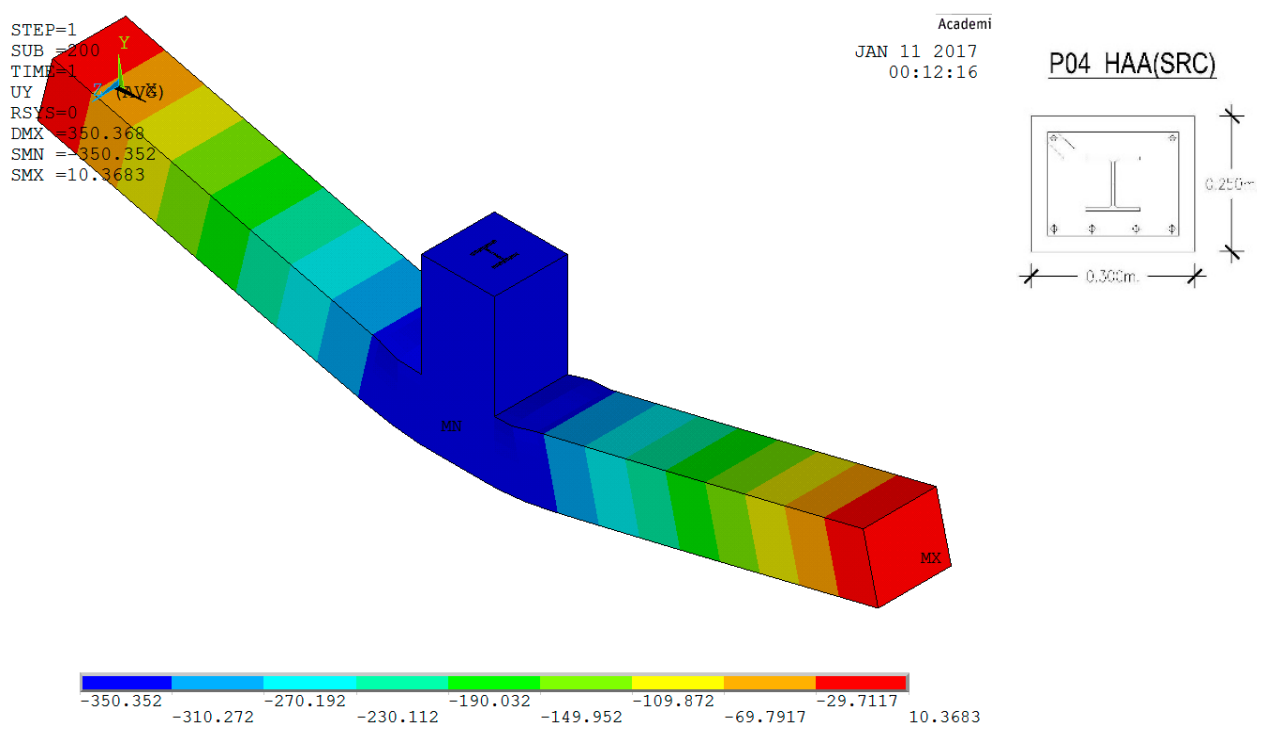

Figure 18. Deflection of the beam (in $\mathrm{mm}$ ) for a $350 \mathrm{~mm}$ deflection.

Figure 19 shows the regions of maximum compression stress in concrete on the upper part of the bar and in the area close to the node.

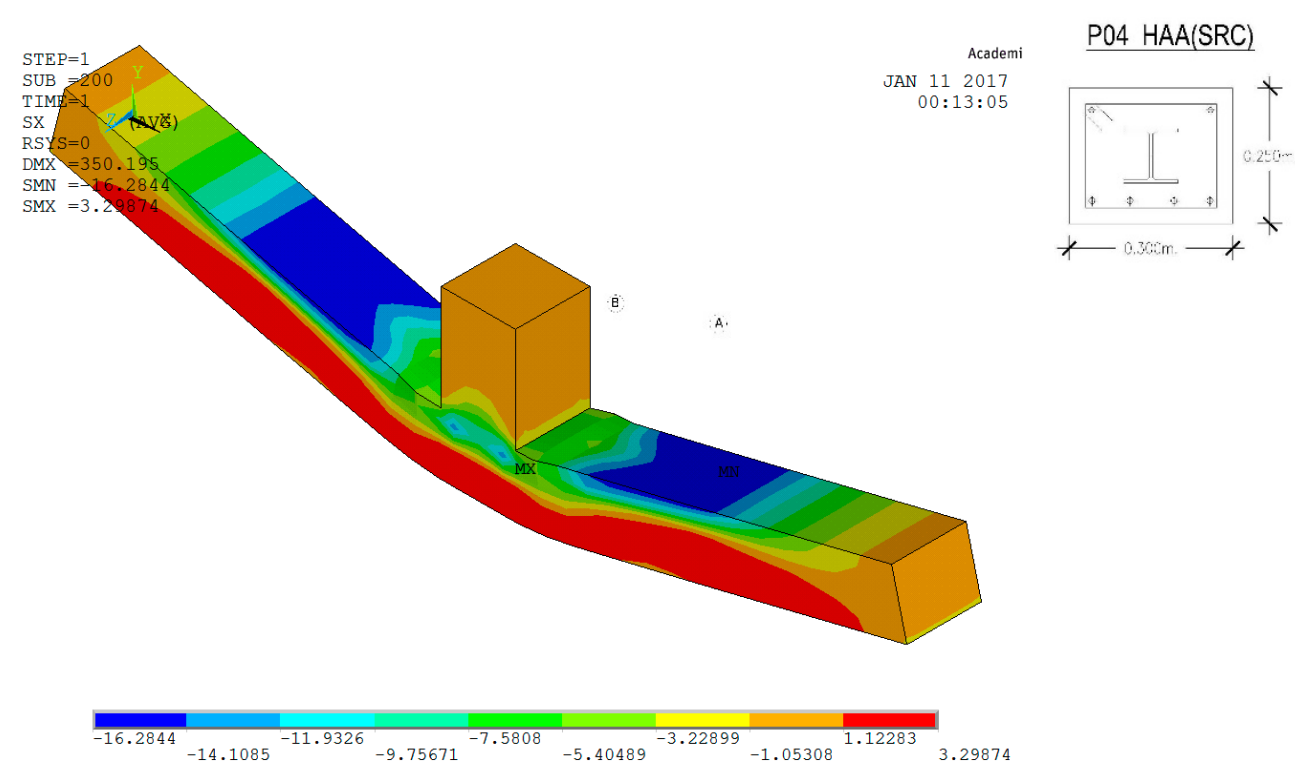

Figure 19. Stresses of concrete in tension and compression for a $350 \mathrm{~mm}$ deflection at the center.

The tensile stresses in concrete were very small in the lower part of the joint and corresponded to the value introduced into the stress-strain diagram. For the maximum deflection, we observed that the maximum compression stress in the concrete was $16.28 \mathrm{MPa}$, which caused cracking and loss of strength as it was introduced into the stress-strain diagram of the material represented in Figure 6.

Figure 20 shows the numerical test with a deflection of $17 \mathrm{~mm}$, in which the maximum stress of compression reached the maximum value of $30.17 \mathrm{MPa}$ in the upper beam part close to the column. This validated the model and demonstrated the decreasing stress with deflection. 


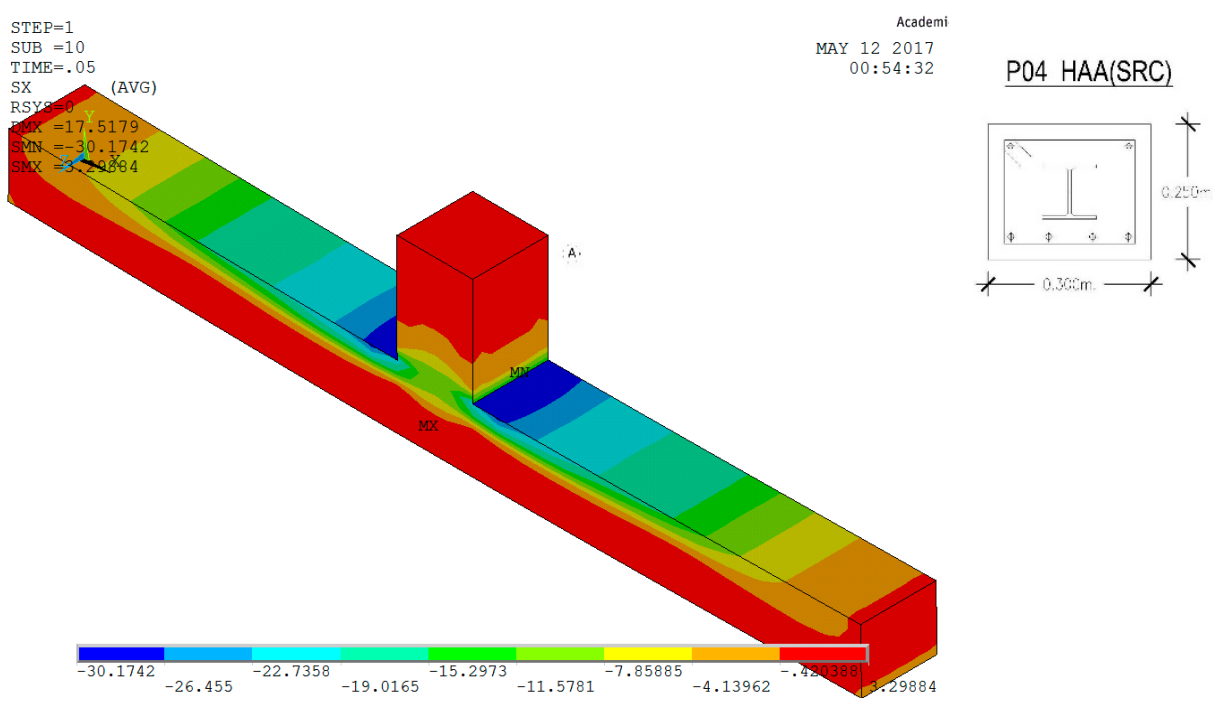

Figure 20. Stress of concrete in tension and compression for a $17 \mathrm{~mm}$ deflection at the center.

The effect of the joint on the stress of the steel profile is seen in Figure 21, with reduced maximum stress compared to prototype P03. In this region, the strength of the materials was not applicable.
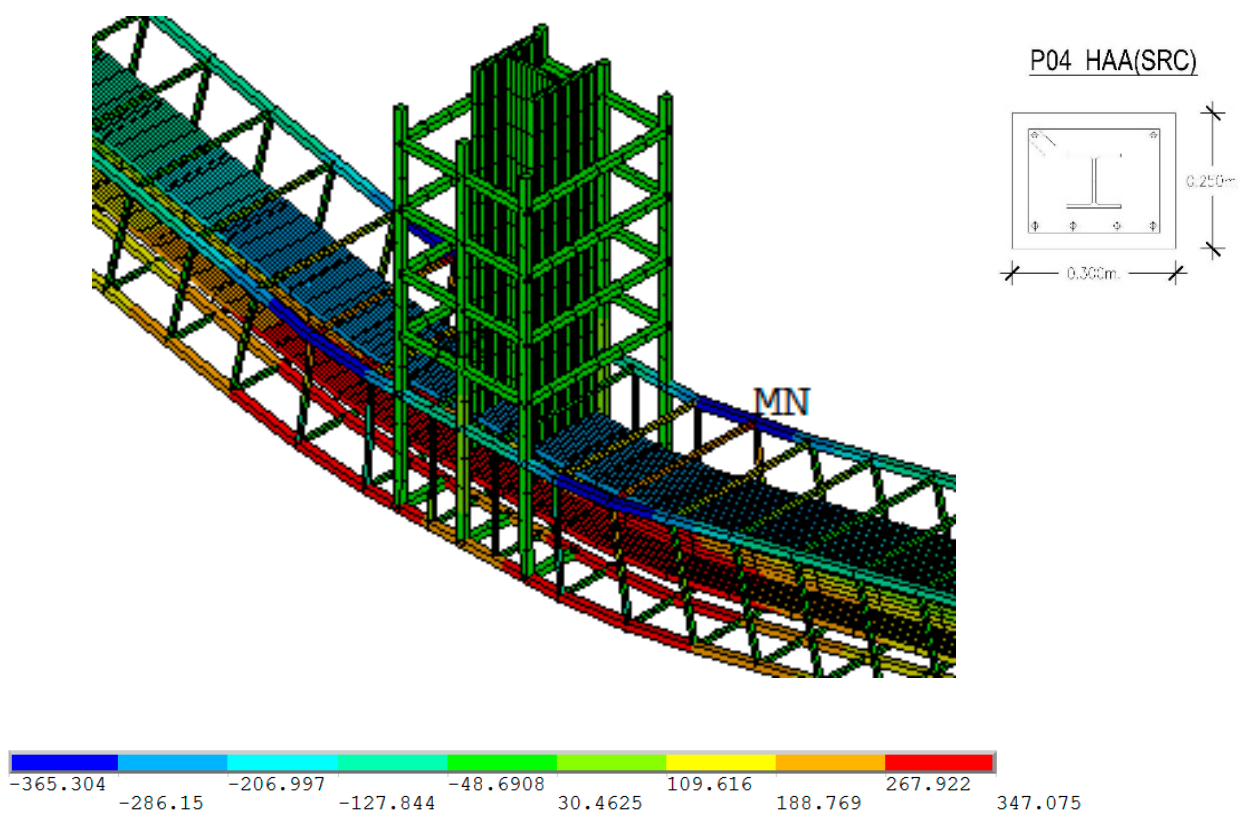

Figure 21. Stress in steel of prototype P04 simulated with a deflection of $350 \mathrm{~mm}$ at the center.

The results obtained were similar to the results of the experimental model of prototype P04 (see Figures 22 and 23). Figure 23 shows the cyclic loading and unloading process and the envelope curve of the real test. 


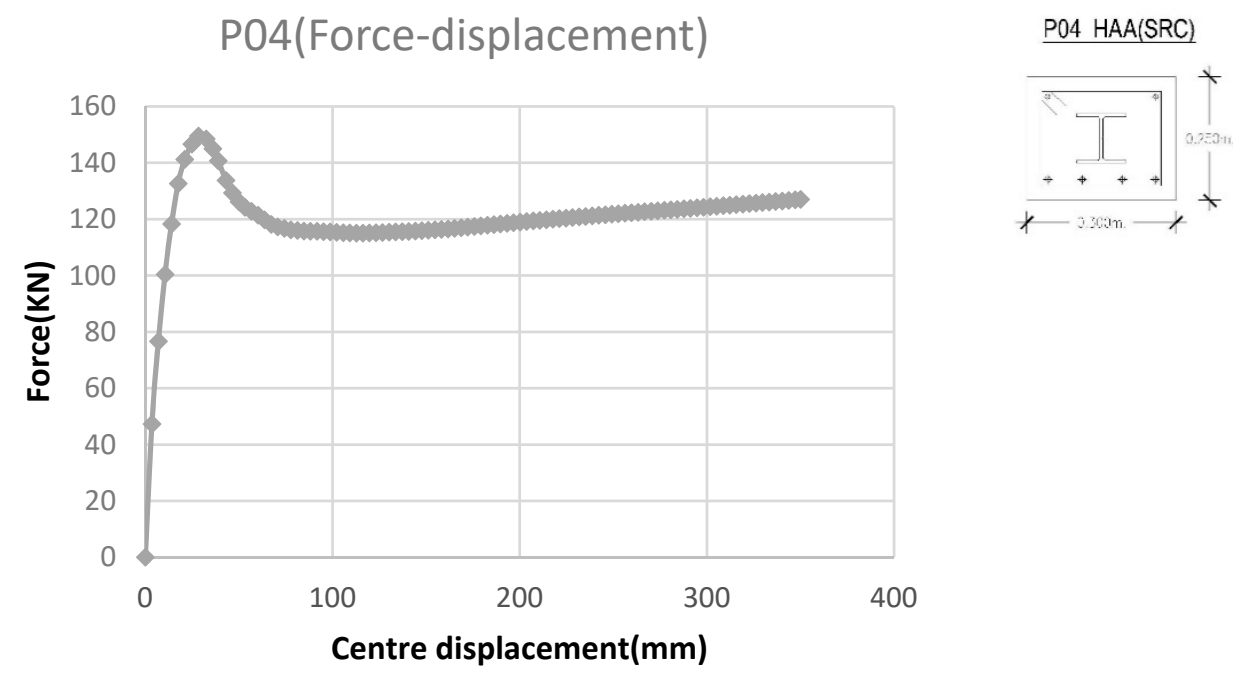

Figure 22. Force-displacement graph of the numerical model of P04.

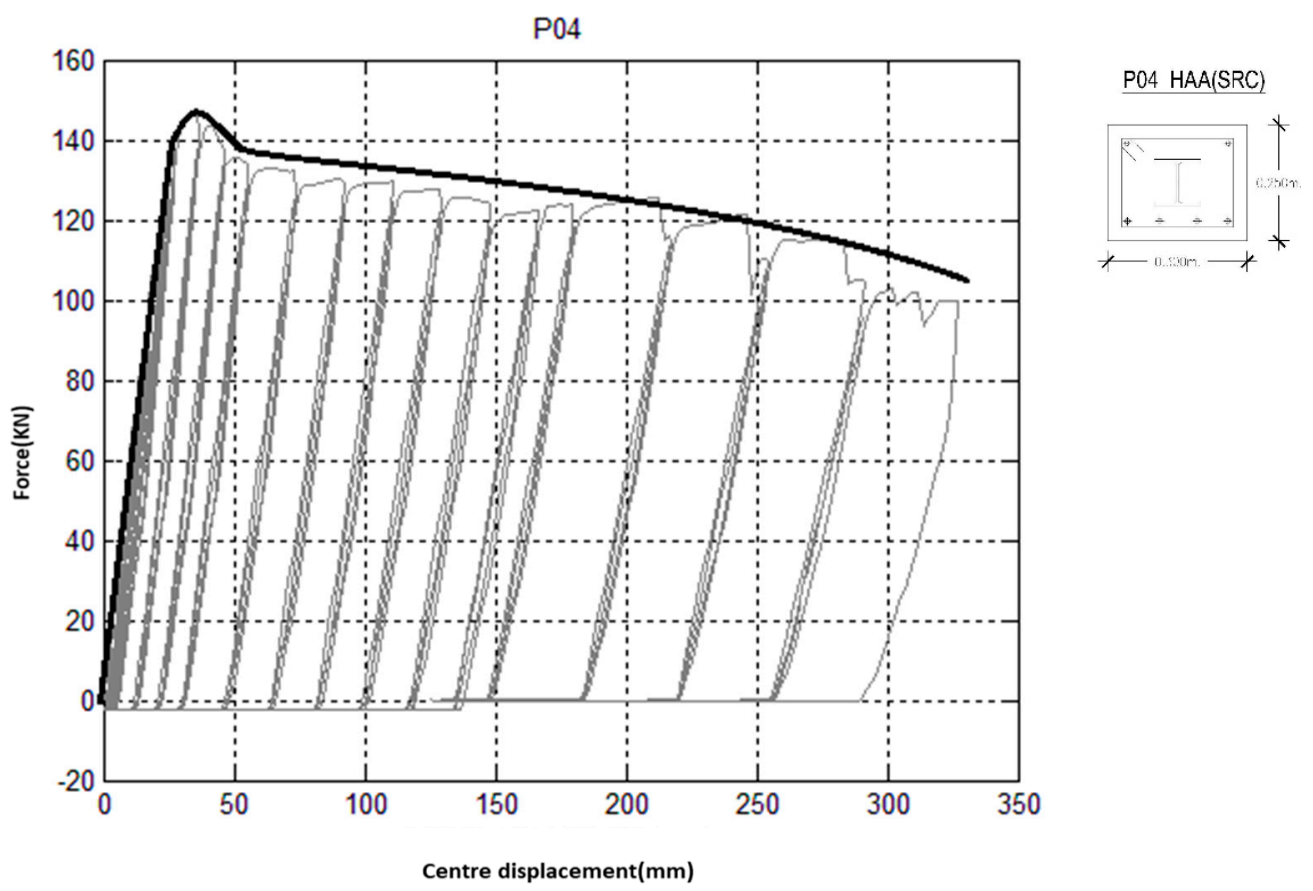

Figure 23. Force-displacement graph of the experimental results of P04.

\subsection{Reinforced Concrete Beam P05}

The third analyzed model had similar strength to model P04 with the embedded HEB100 cross-section, but without the metal section, and with greater reinforcement than model P03. The maximum deflection imposed was $200 \mathrm{~mm}$, the same as in the experimental test (Figure 24). 

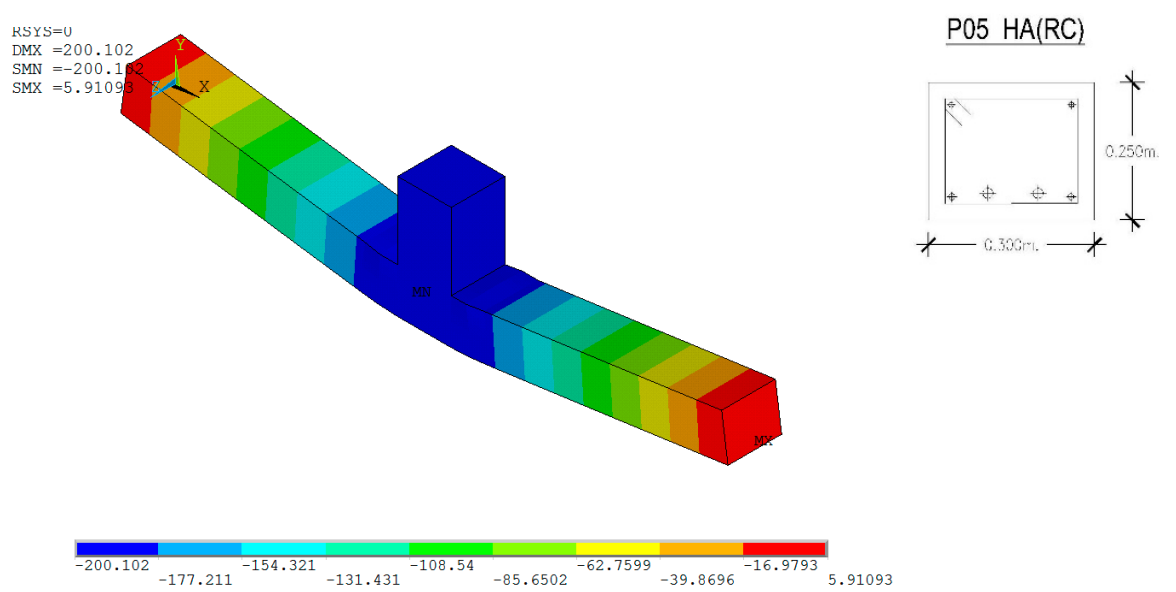

Figure 24. Deflections in the beam (in $\mathrm{mm}$ ).

Figure 25 shows the regions of compression and tension stresses in the concrete.

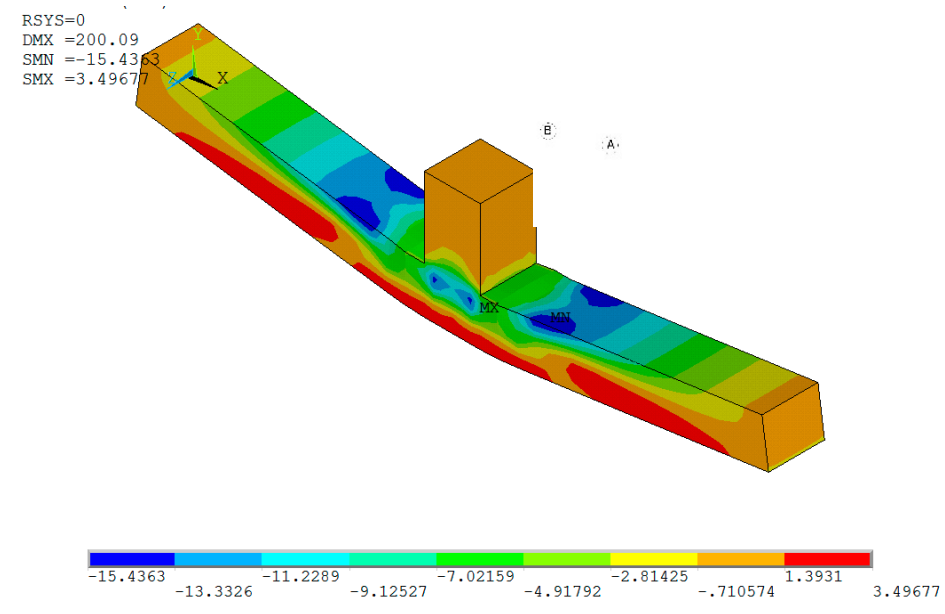

P05 HA(RC)

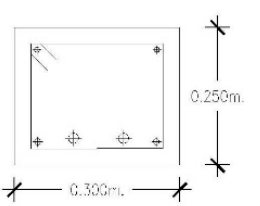

Figure 25. Compression and tension stresses in concrete for a deflection of $200 \mathrm{~mm}$.

The plasticity of the upper and lower reinforcements is observed in Figure 26, which is superior to the previous model, up to $372 \mathrm{MPa}$ for compression.
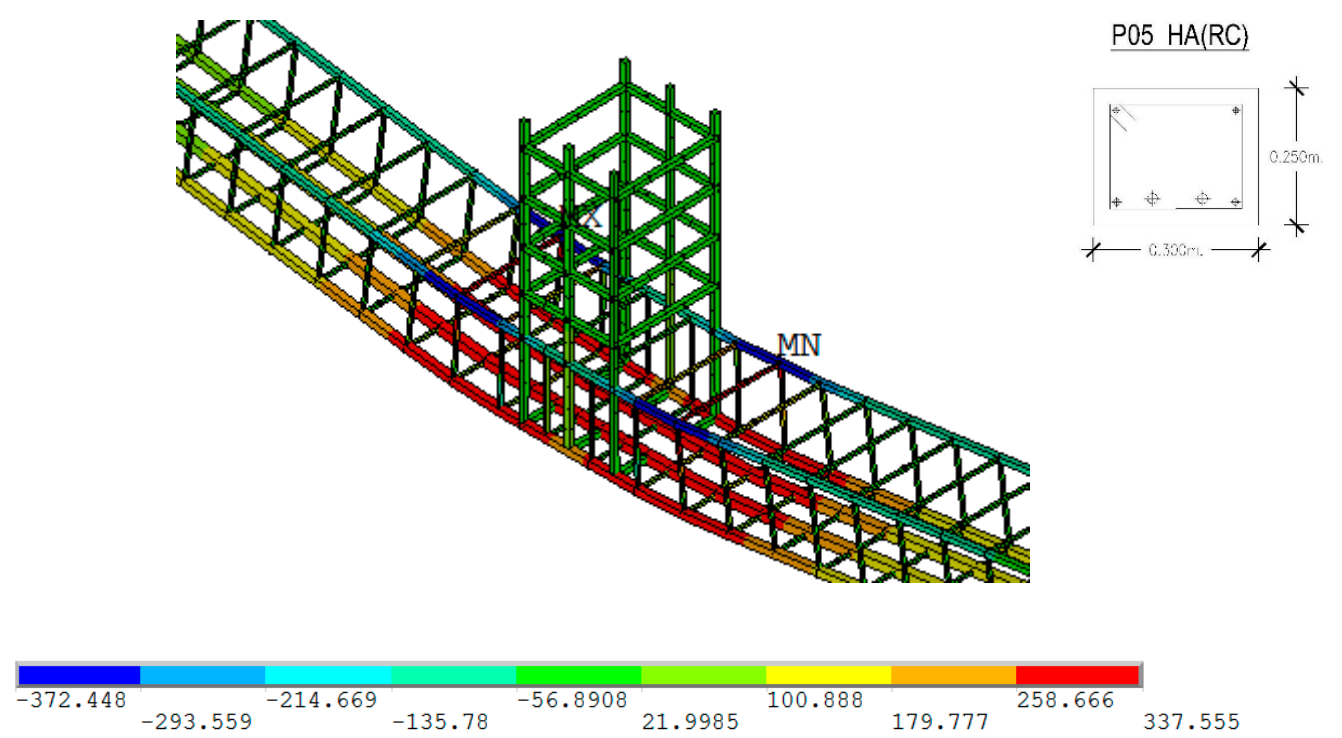

Figure 26. Stress in steel bars of prototype P05 simulated for a $200 \mathrm{~mm}$ deflection. 
The obtained results were similar to those of the numerical test of prototype P05 (Figures 27 and 28). Figure 28 shows the cyclic loading and unloading process and the envelope curve of the real test.

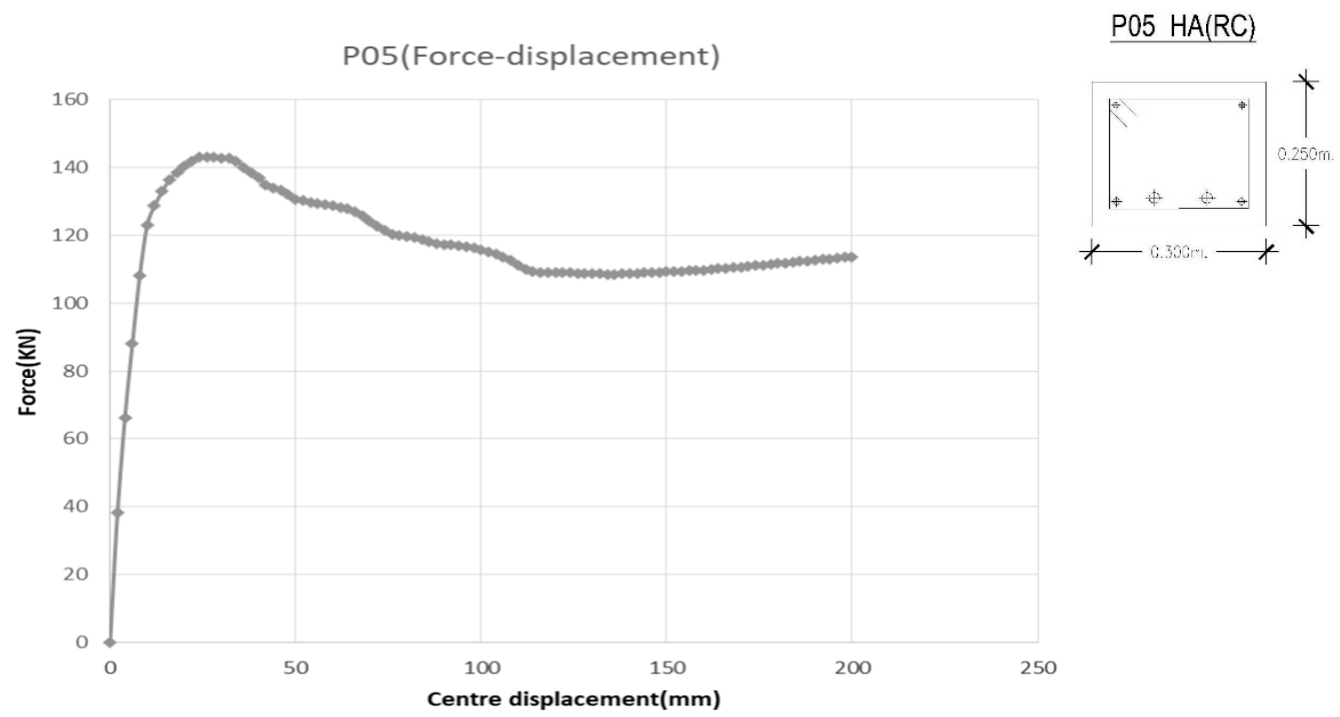

Figure 27. Force-displacement graph of numerical model of P05.

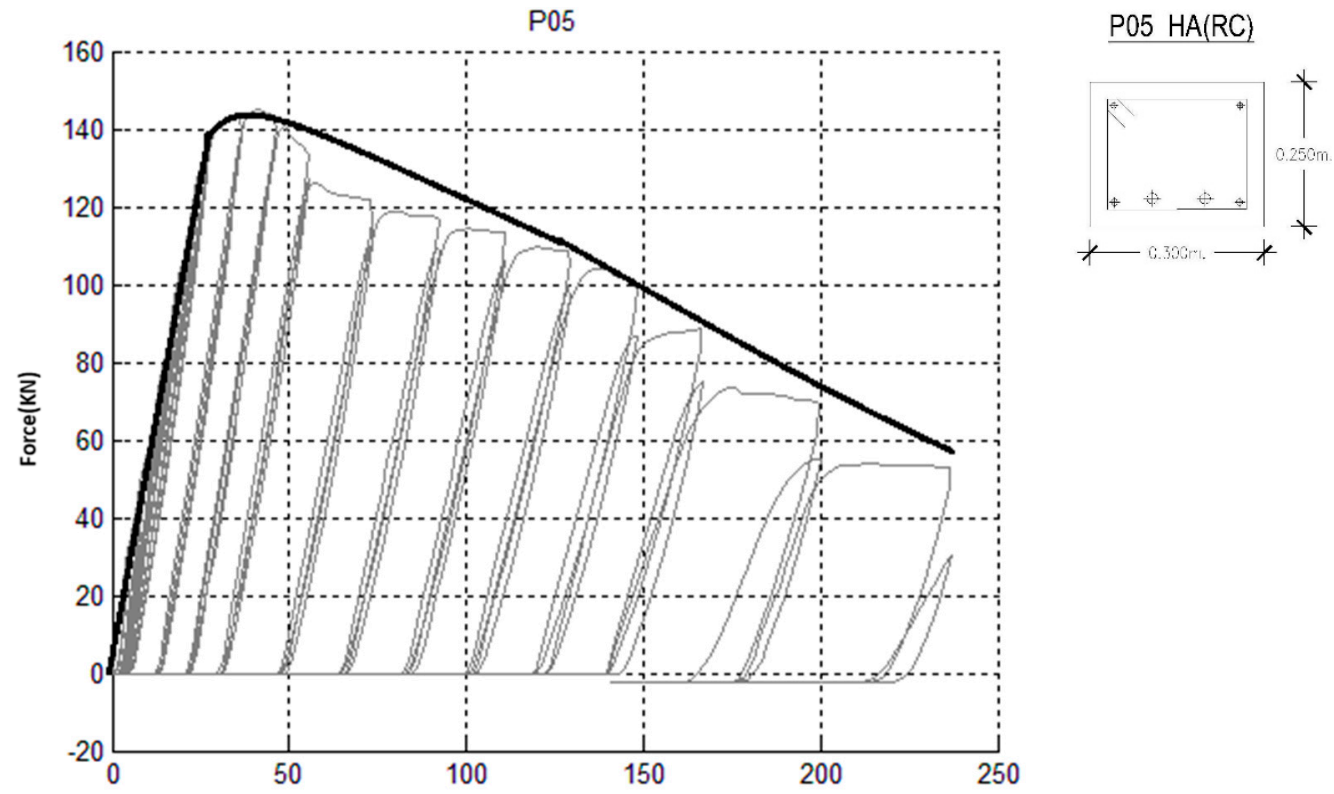

Figure 28. Force-displacement graph of experimental results of P05.

\subsection{M- $\chi$ Nonlinear Graph}

A moment-curvature graph can be obtained in the section next to the joint to copy the characteristics of the analyzed models and for nonlinear calculations of a structure made with prismatic elements. The curvature caused by the bending moment is defined as the relative rotation of the faces of a slice of differential length per unit length. The overturn induced by a moment in a given section can be analyzed (Figure 29). For the same bending moments, the curvature is higher if the section is more flexible. 


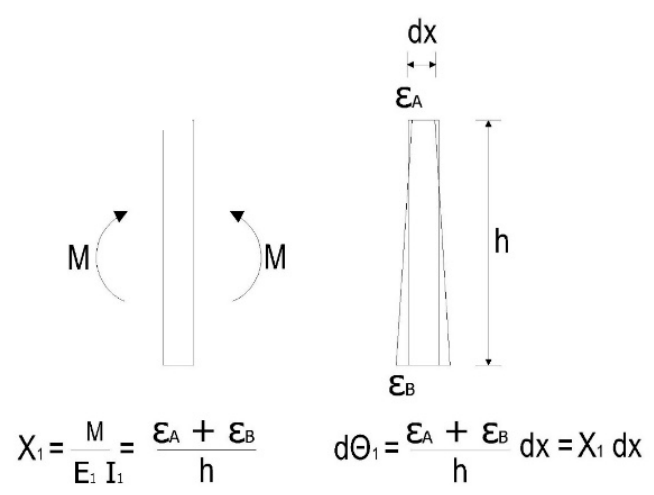

Figure 29. Analysis of the curvature of a section.

This novel procedure consisted of a three-dimensional finite element model validated by the experimental models to obtain the moment-curvature graph from the strains and moments in the section. The moment-curvature graph was obtained from the solid model. The curvature obtained was the difference of the strain on the x-axis of the upper and lower nodes of the section at $100 \mathrm{~mm}$ of the face of the column divided by the height of the section. The moment-curvature graph allowed bar structures to be simulated with a nonlinear analysis, like the moment of the section was related to its curvature, a relationship in which the reduction of the inertia of concrete by cracking was implicit.

Different procedures to obtain the moment-curvature graph in reinforced concrete were analyzed. The moment-curvature graph of the section can be obtained with computer programs, in which a section is defined with the properties of the materials that compose it. From the validated model, the moment-curvature graph was obtained in different sections at $1.4 \mathrm{~m}$ and $1.3 \mathrm{~m}$ from the support. The section at $1.4 \mathrm{~m}$ was considered valid to obtain the graph because it was plastified and reached the highest values of the moment and curvature. The moment-curvature values at $1.5 \mathrm{~m}$ from the support were not valid when the influence of column stiffness was checked.

Figure 30 shows the moment-curvature graphs of specimens P03, P04, and P05 in the section $1400 \mathrm{~mm}$ from the support, which can be used to analyze frames of bars by considering post-critical behavior. The graph of prototype P04 shows a wider range of ductility compared to the other two, where failure prevented higher strains from being reached. It is noteworthy that for materials like concrete, which deteriorates with big strains, the moment-curvature graph decreased for large curvatures after it was verified that the behavior of the beam was similar to what is seen in the stress-strain diagram in this case (Figure 30).

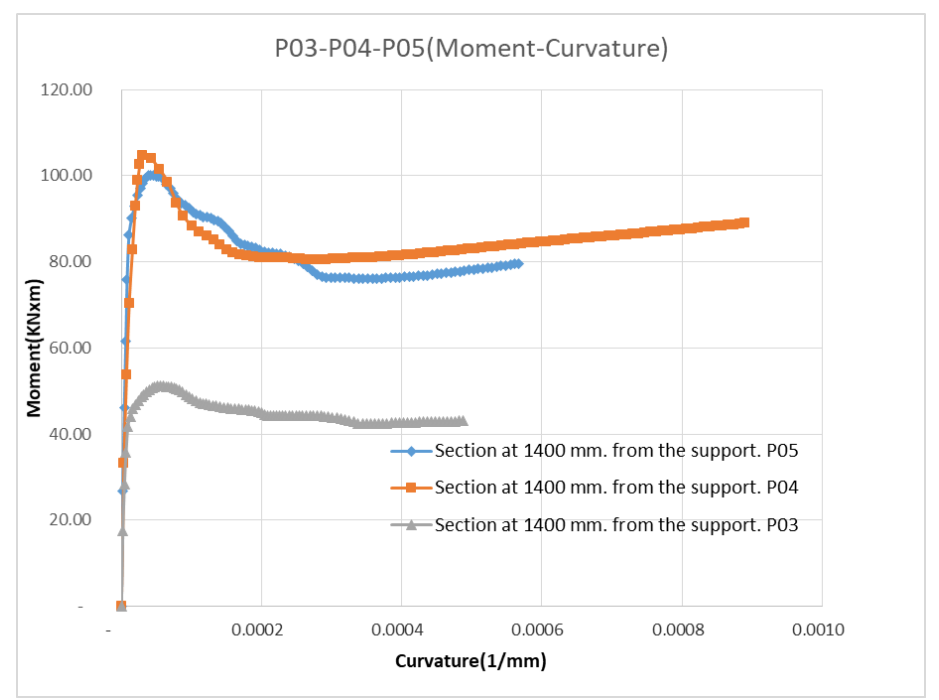

Figure 30. Moment-curvature graph of P03, P04, and P05. 


\section{Conclusions}

Based on the results obtained in this paper, the following comments and conclusions are presented:

- The analysis was conducted by three-dimensional finite element models of specimens P03, P04, and P05, which were analyzed experimentally in previous research.

- The force-displacement graph results obtained in the three models were similar to the experimental tests.

- The increase of force in the plastic region when it reached the large displacement was due to descending branches in the steel not being included, which generated hardening for large strains and did not include loss of strength due to failure. This will be studied in future research.

- The model with the steel section reinforcement worked with less stress, but with more length affected. In the model with no reinforcement section, the damage was concentrated more on the part of the joint, while a force distribution effect along the beam was obtained for steel, with more rigidity and strength for the model with the metal cross-section than the model without it.

- The analysis of the stress-strain graphs of the materials for large deflections to conduct nonlinear simulations of large displacements was essential to predict the descending branches in the plastic region.

- A very interesting capability of this model was that it generated decreasing moment-curvature graphs due to partial or total fatigue or failure of materials. This is a novel procedure, which is easy to apply.

- The graphic moment-curvature of specimens P03, P04, and P05 in the section to $1400 \mathrm{~mm}$ supports entering the data in the following model of bars. The graph of P04 allows a greater range of ductility than the other two, where the break prevented reaching greater strains.

- Simulation with the numerical models is able to analyze complex situations. In particular, the model of simplified bars with the relationship of moment-curvature allows nonlinear calculation until reaching large displacements, taking into account the reduction of rigidity because of the cracking of the concrete.

- A new procedure was developed to obtain the moment-curvature graphs of the sections from the numerical models. The moment-curvature diagram can be used in the simplified bar analysis by contemplating post-critical behavior in future research.

Author Contributions: Formal analysis, J.S. and J.M.G.; Investigation, I.M. and R.I.; Writing—original draft, I.M.; Writing-review \& editing, I.M., R.I. and E.J.

Funding: This research received no external funding.

Conflicts of Interest: The authors declare no conflict of interest.

\section{References}

1. Akiyama, H. Metodología de Proyecto Sismorresistente de Edificios Basada en el Balance Energético; Editorial Reverté. S.A.: Barcelona, Sapin, 2003.

2. Chen, C.C.; Lin, K.T. Behavior and strength of steel reinforced concrete beam-column joints with two-side force inputs. J. Constr. Steel Res. 2009, 65, 641-649. [CrossRef]

3. Chen, C.-C.; Suswanto, B.; Lin, Y.-J. Behavior and strength of steel reinforced concrete beam-column joints with single-side force inputs. J. Constr. Steel Res. 2009, 65, 1569-1581. [CrossRef]

4. Oliver, J.; Cervera, M.; Oller, S.; Lubliner, J. Isotropic damage models and smeared crack analysis of concrete. In Proceedings of the II International Conference on Computer Aided Analysis and Design of Concrete Structures, SCI-C'90, At Zell am See, Austria, 4-6 April 1990.

5. Chaudhari, S.V.; Chakrabarti, M.A. Modeling of concrete for nonlinear analysis using finite element code ABAQUS. Int. J. Comput. Appl. 2012, 44, 14-18. 
6. Jirásek, M. Damage and Smeared Crack Models. In Numerical Modeling of Concrete Cracking; Hofstetter, G., Meschke, G., Eds.; CISM International Centre for Mechanical Sciences, Springer: Vienna, Austria, 2011; Volume 532.

7. Chen, W.F.; Han, D.J. Plasticity for Structural Engineers; Springer: New York, NY, USA, 1988.

8. Hjelm, H.E. Yield Surface for Gray Cast iron under Biaxial Stress. J. Eng. Mater. Technol. 1994, 116, $148-154$. [CrossRef]

9. Sinaei, H.; Shariati, M.; Abna, A.H.; Aghaei, M.; Shariati, A. Evaluation of reinforced concrete beam behaviour using finite element analysis by ABAQUS. Sci. Res. Essays 2012, 7, 2002-2009.

10. López, N. Análisis de la Aplicación del Método de los Elementos Finitos al Modelado de Elementos de Hormigón Armado. Ph.D. Thesis, Universidad da Coruña, A Coruña, Spain, 2008.

11. Fanning, P. Nonlinear models of reinforced and post-tensioned concrete beams. Electron. J. Struct. Eng. 2001, 1,111-119.

12. Wakabayashi, M. Diseño de Edificios Resistentes a los Terremotos; McGraw-Colina: New York, NY, USA, 1986.

13. Uy, B.; Patel, V.; Li, D.; Aslani, F. Behaviour and design of connections for demountable steel and composite structures. Structures 2017, 9, 1-12. [CrossRef]

14. Soti, R.; Barbosa, A.R.; Stavridis, A. Numerical Modeling of URM Infill Walls Retrofitted with Embedded Reinforcing Steel. In Proceedings of the 10th National Conference in Earthquake Engineering, Anchorage, AK, USA, 21-25 July 2014; Earthquake Engineering Research Institute: Anchorage, AK, USA, 2014.

15. Suswanto, B. Shear Behavior and Strength of Steel Reinforced Concrete Beam-Column Joints with Single-Side Force Inputs. Ph.D. Thesis, Department of Civil Engineering, Sepuluh Nopember Institute of Technology (ITS), Surabaya, Indonesia, 1998.

16. Anastasiadis, A.; Mosoarca, M.; Gioncu, V. Prediction of available rotation capacity and ductility of wide-flange beams. J. Constr. Steel Res. 2012, 68, 176-191. [CrossRef]

17. Forner, E.F. Análisis de Soportes Mixtos Sometidos a Flexocompresión Esviada. Ph.D. Thesis, Universidad Politécnica de Valencia, Valencia, Spain, 2011.

18. Bossio, A.; Fabbrocino, F.; Lignola, G.P.; Prota, A.; Manfredi, G. Design Oriented Model for the Assessment of T-Shaped Beam-Column Joints in Reinforced Concrete Frames. Buildings 2017, 7, 118. [CrossRef]

19. Bossio, A.; Fabbrocino, F.; Lignola, G.P.; Prota, A.; Manfredi, G. Simplified Model for Strengthening Design of Beam-Column Internal Joints in Reinforced Concrete Frames. Polymers 2015, 7, 1732-1754. [CrossRef]

20. Santarsiero, G. FE Modelling of the Seismic Behavior of Wide Beam-Column Joints Strengthened with CFRP Systems. Buildings 2018, 8, 31. [CrossRef]

21. Kabir, M.R.; Alam, M.S.; Said, A.M.; Ayad, A. Performance of Hybrid Reinforced Concrete Beam Column Joint: A Critical Review. Fibers 2016, 4, 13. [CrossRef]

22. Tran, M.-T.; Bui, Q.-B.; Sentosa, B.; Nguyen, N.-T.; Duong, T.-H.; Plé, O. Sustainable RC Beam-Column Connections with Headed Bars: A Formula for Shear Strength Evaluation. Sustainability 2018, 10, 401. [CrossRef]

23. Gribniak, V.; Tamulenas, V.; Ng, P.-L.; Arnautov, A.K.; Gudonis, E.; Misiunaite, I. Mechanical Behavior of Steel Fiber-Reinforced Concrete Beams Bonded with External Carbon Fiber Sheets. Materials 2017, 10, 666. [CrossRef] [PubMed]

24. Du, Y.; Zhang, X.; Liu, L.; Zhou, F.; Zhu, D.; Pan, W. Flexural Behaviour of Carbon Textile-Reinforced Concrete with Prestress and Steel Fibres. Polymers 2018, 10, 98. [CrossRef]

25. Adelzadeh, M.; Hajiloo, H.; Green, M.F. Numerical Study of FRP Reinforced Concrete Slabs at Elevated Temperature. Polymers 2014, 6, 408-422. [CrossRef]

26. Li, J.; Wang, Y.; Lu, Z.; Li, J. Experimental Study and Numerical Simulation of a Laminated Reinforced Concrete Shear Wall with a Vertical Seam. Appl. Sci. 2017, 7, 629.

27. Model for Moment-Curvature Relationship of Reinforced Concrete Sections. Math. Comput. Appl. 2010, 15, 66-78.

28. Montava, I. Estudio del Comportamiento de Estructuras de Hormigón Armado con Perfiles Metálicos Completamente Embebidos. PhD Thesis, Universidad de Alicante, Alicante, Spain, 2017.

29. EHE-08-Instrucción de Hormigón Estructural; Ministerio de Fomento: Madrid, Spain, 2008. 
30. EN 1993 1-1 (English): Eurocode 3: Design of Steel Structures; The European Union: Brussels, Belgium, 1993.

31. EAE-Instrucción de Acero Estructural; Ministerio de Fomento: Madrid, Spain, 2010.

(C) 2019 by the authors. Licensee MDPI, Basel, Switzerland. This article is an open access article distributed under the terms and conditions of the Creative Commons Attribution (CC BY) license (http:/ / creativecommons.org/licenses/by/4.0/). 